\title{
Model oxide-supported metal catalysts - comparison of ultrahigh vacuum and solution based preparation of Pd nanoparticles on a single-crystalline oxide substrate
}

\author{
Hui-Feng Wang, William E. Kaden, Rhys Dowler, Martin Sterrer* and \\ Hans-Joachim Freund
}

Received 7th May 2012, Accepted 2nd July 2012

DOI: $10.1039 / \mathrm{c} 2 \mathrm{cp} 41459 \mathrm{~g}$

Using single-crystalline $\mathrm{Fe}_{3} \mathrm{O}_{4}(111)$ films grown over $\mathrm{Pt}(111)$ in UHV as a model-support, we have characterized the nucleation behaviour and chemical properties of Pd particles grown over the film using different deposition techniques with scanning tunnelling microscopy and X-ray photoelectron spectroscopy. Comparison of $\mathrm{Pd} / \mathrm{Fe}_{3} \mathrm{O}_{4}$ samples created via $\mathrm{Pd}$ evaporation under UHV conditions and those resulting from the solution deposition of Pd-hydroxo complexes reveals that changes in the interfacial functionalization of such samples (i.e. roughening and hydroxylation) govern the differences in Pd nucleation behavior observed over pristine oxides relative to those exposed to alkaline solutions. Furthermore, it appears that other differences in the nature of the Pd precursor state (i.e. gas-phase Pd in UHV vs. $\left[\mathrm{Pd}(\mathrm{OH})_{2}\right]_{n}$ aqueous complexes) play a negligible role in Pd nucleation and growth behaviour at elevated temperatures in UHV, suggesting facile decomposition of the Pd complexes deposited from the liquid phase. Applying temperature programmed desorption and infrared spectroscopy to probe the $\mathrm{CO}$ chemisorption properties of such samples after reduction in different reagents $\left(\mathrm{CO}, \mathrm{H}_{2}\right)$ shows the formation of bimetallic $\mathrm{PdFe}$ alloys following reduction in $\mathrm{H}_{2}$, but monometallic Pd particles after $\mathrm{CO}$ reduction.

\section{Introduction}

Due to the complexity of technically relevant heterogeneous catalysts, for which direct correlations between chemical activity and the fundamental properties controlling it have proven difficult to attain, strong efforts have been put into the design of model catalyst systems that grasp the essential aspects of technical systems, while remaining simple enough to allow for the application of advanced analysis tools. ${ }^{1}$ In this vein, oxide-supported metal nanoparticles have received particular attention in the model catalysis community over the past $1-2$ decades. Following the classical surface-science approach, which utilizes atomically well-defined metal single-crystal surfaces to model the active sites in conventional catalysts, ${ }^{2,3}$ a high degree of uniformity of both the metal nanoparticles and the support surfaces is desirable when forming heterogeneous model systems as well. To this end, ultrahigh vacuum (UHV) based surface-science studies, utilizing clean oxide surfaces as supports for metal particles, have greatly contributed to the understanding of many catalyst systems. ${ }^{4-8}$

Department of Chemical Physics, Fritz-Haber-Institut der Max-Planck-Gesellschaft, Faradayweg 4-6, 14195 Berlin, Germany. E-mail: sterrer@fhi-berlin.mpg.de
In such studies, metal particles are typically created via metal evaporation and sample annealing, with properties, such as average particle size and morphology, loosely controlled by the amount of metal dosed and the sample temperatures employed. ${ }^{9,10}$ The utility of this approach, which yields UHV-clean, contaminant-free model catalyst surfaces, has been demonstrated in a large number of studies. ${ }^{4-8}$ In spite of the advantages inherent to this methodology, concerns may be raised over how well the properties of samples created via such simplified UHV procedures represent those of samples produced via technically applied wet chemical procedures, such as impregnation, deposition-precipitation, or ion exchange. In this study, our aim is to make direct comparisons between samples created via conventional UHV, and wet chemical metal loading techniques, to determine how differences in the nature of the precursor medium affect the nucleation and chemical behaviour of metals deposited on oxides. As an example, results for $\mathrm{Pd}$ particles grown over $\mathrm{Fe}_{3} \mathrm{O}_{4}(111)$ single-crystalline supports will be presented.

$\mathrm{PdCl}_{2}$ is a frequently used precursor in the preparation of oxide-supported $\mathrm{Pd}$ catalysts, and a typical impregnation procedure involves contact of an acidic $\mathrm{PdCl}_{2}$ precursor solution with the support. As mentioned in several studies, chloride, which is difficult to remove from the catalyst surface 
after impregnation with $\left[\mathrm{PdCl}_{4}\right]^{2-}$, is presumed to have a negative effect on catalytic activity and selectivity. ${ }^{1-13}$ To avoid chloride poisoning, different precursor salts may be used, e.g. $\mathrm{Pd}\left(\mathrm{NO}_{3}\right)_{2}$, or the preparation conditions may be altered. One of the alternatives is deposition-precipitation, where selective adsorption of Pd-hydroxo complexes is achieved by alkaline hydrolysis of the $\mathrm{PdCl}_{2}$ precursor. This method has been applied for Pd deposition onto both carbon and oxide supports, ${ }^{14-19}$ and, since it results in a surface free of residues from the precursor solution $\left(\mathrm{Na}^{+}, \mathrm{Cl}^{-}\right)$, it is ideally suited for our purposes (i.e., comparison with samples created exclusively within UHV environments).

An in-depth description of deposition-precipitation of the $\mathrm{Na}_{2} \mathrm{PdCl}_{4}$ precursor on alumina and silica-alumina powder supports has been provided by Agostini et al., who used an extensive set of experimental techniques to characterize the Pd species present in the various stages of preparation. ${ }^{16}$ Deposition of Pd-hydroxide is usually achieved by slowly increasing the $\mathrm{pH}$ of an acidic $\mathrm{PdCl}_{2}$ precursor solution to about $\mathrm{pH} 4-5$, whereupon precipitation of the hydroxide on the support occurs. Alternatively, a Pd-hydroxide precipitate can be obtained by directly contacting the support with an alkaline Pd solution of about $\mathrm{pH}$ 10. Transformation of the Pd-hydroxide, or -oxide, precursor into metallic nanoparticles is accomplished by reduction in an $\mathrm{H}_{2}$ atmosphere at room temperature or decomposition at elevated temperature within vacuum. Under more harsh reduction conditions, i.e., reduction in hydrogen at elevated temperature, supported Pd catalysts may be driven into an SMSI state (SMSI = strong metal support interaction). Typical manifestations of SMSI include partial decoration or complete encapsulation of the metal particle by a reduced oxide film (e.g., $\mathrm{Pd} / \mathrm{TiO}_{2},{ }^{20-22}$ $\left.\mathrm{Pd} / \mathrm{CeO}_{2},{ }^{23,24} \mathrm{Pd} / \mathrm{Fe}_{2} \mathrm{O}_{3},{ }^{25} \mathrm{Pd} / \mathrm{silica}^{26}\right)$ and alloying (e.g. $\mathrm{Pd} / \mathrm{ZnO},{ }^{27}$ $\mathrm{Pd} / \mathrm{Ga}_{2} \mathrm{O}_{3}{ }^{28}$ ).

The choice to use $\mathrm{Fe}_{3} \mathrm{O}_{4}$ films in this work stems from the unique redox properties and oxygen storage capacity of ironoxides, for which they have become increasingly attractive support materials for heterogeneous catalysts. For example, $\mathrm{FeO}_{x}$-supported $\mathrm{Au}$ and $\mathrm{Pd}$ nanoparticles show high activity towards low-temperature $\mathrm{CO}$ oxidation. ${ }^{29-31}$ From a technological point of view, magnetite $\left(\mathrm{Fe}_{3} \mathrm{O}_{4}\right)$ has strong potential as a support for "heterogenized" homogeneous Pd catalysts because it allows easy magnetic separation of the catalyst from the reaction mixture. ${ }^{32}$ Furthermore, UHV model systems consisting of Pd nanoparticles supported by single-crystalline $\mathrm{Fe}_{3} \mathrm{O}_{4}(111)$ have already been extensively investigated within our department with respect to particle size-dependent adsorption properties, and catalytic activity towards $\mathrm{CO}$ oxidation and alkene hydrogenation reactions. ${ }^{33-35}$

\section{Experimental details}

\section{Sample preparation}

Single-crystalline $\mathrm{Fe}_{3} \mathrm{O}_{4}(111)$ thin films were used in the present study as the support for Pd nanoparticles. The preparation of these films was carried out within UHV over Pt(111) single-crystal substrates, using well established recipes, which have been described in detail elsewhere. ${ }^{36}$ The UHV chamber used is equipped with a sputter gun, metal evaporator, low energy electron diffraction (LEED) apparatus, X-ray photoelectron spectroscopy (XPS) setup, and a mass spectrometer for temperature programmed desorption (TPD). Briefly, the recipe employed is as follows: first, an $\mathrm{FeO}(111)$ monolayer (ML) film was grown over clean $\mathrm{Pt}(111)$ by deposition of $1 \mathrm{ML} \mathrm{Fe}$ (where $1 \mathrm{ML}$ corresponds to a closed-packed layer of Fe on $\mathrm{Pt}(111))$ at room temperature (RT) followed by oxidation at $1000 \mathrm{~K}$ in $1 \times 10^{-6} \mathrm{mbar}_{2}$. Over the $\mathrm{FeO}(111)$ layer, a $10 \mathrm{~nm}$ thick $\mathrm{Fe}_{3} \mathrm{O}_{4}(111)$ film was grown by repeated cycles $(4 \times)$ of $\mathrm{Fe}$ deposition $(8 \mathrm{ML})$ at $\mathrm{RT}$ and oxidation at $900 \mathrm{~K}$, and completed by final oxidation at $1000 \mathrm{~K}$.

For wet $\mathrm{Pd}$ deposition, the $\mathrm{Fe}_{3} \mathrm{O}_{4}(111)$ sample was transferred out of the UHV chamber and contacted with Pd containing precursor solution in an ambient atmosphere. The precursor solution was prepared from solid $\mathrm{PdCl}_{2}(99.9 \%$, Alfa Aesar), which was first dissolved in $\mathrm{HCl}$ and then adjusted to a final $\mathrm{pH}$ of $\sim 10$ with $\mathrm{NaOH}$. $\mathrm{pH}$ was checked with $\mathrm{pH}$ paper strips. The Pd concentration used in the present study was $2 \mathrm{mM}$, and flocculation of $\mathrm{Pd}(\mathrm{OH})_{2}$, which readily occurs at room temperature around $\mathrm{pH} 6$, was avoided by adding the balance $\mathrm{NaOH}$ solution as rapidly as possible. After contacting the $\mathrm{Fe}_{3} \mathrm{O}_{4}(111)$ surface with precursor solution for the desired time, the solution was removed and the single crystal surface washed three times with $3 \mathrm{ml}$ of ultra-pure water. Finally, the sample was dried at RT under a He flow. Further sample treatments were carried out in the UHV chamber, and consisted of thermal reduction up to $600 \mathrm{~K}$ in UHV, oxidation $\left(1 \times 10^{-6} \mathrm{mbar}_{2}, 600 \mathrm{~K}\right)$ and reduction $\left(1 \times 10^{-6} \mathrm{mbar}\right.$ $\mathrm{CO}$ or $\mathrm{H}_{2}, 500 \mathrm{~K}$ ). In addition to the samples prepared using liquid phase precursors, two other $\mathrm{Pd} / \mathrm{Fe}_{3} \mathrm{O}_{4}(111)$ samples were investigated: one was exclusively prepared in UHV via physical vapor deposition (PVD) of $\mathrm{Pd}$ onto a clean $\mathrm{Fe}_{3} \mathrm{O}_{4}(111)$ surface, and the other made use of the same PVD procedure after first exposing the film to $\mathrm{NaOH}(\mathrm{pH} 12)$.

\section{Sample characterization}

STM images of various $\mathrm{Pd} / \mathrm{Fe}_{3} \mathrm{O}_{4}$ and $\mathrm{Fe}_{3} \mathrm{O}_{4}$ samples were obtained under ambient conditions using a Wandelt-type electrochemical $\mathrm{STM}^{37}$ and electrochemically etched $\mathrm{Pt}-\mathrm{Ir}$ tips. The tunneling parameters for the images reported here are: $i_{\mathrm{t}}=0.1 \mathrm{nA}$ and $U_{\mathrm{t}}=-0.3 \mathrm{~V}$. XPS spectra were acquired in UHV using an $\mathrm{Al} \mathrm{K} \alpha \mathrm{X}$-ray source and a hemispherical analyzer (SPECS Phoibos 150). TPD spectra were collected using a heating ramp of $2 \mathrm{~K} \mathrm{~s}^{-1}$ after exposure to $10 \mathrm{~L}$ (Langmuir) ${ }^{13} \mathrm{CO}$ at room temperature. IRAS spectra were taken in a separate UHV chamber equipped with a Bruker IFS/66v spectrometer and an MCT detector. For IRAS measurements, the sample was cooled to $80 \mathrm{~K}$ and exposed to $10 \mathrm{~L} \mathrm{CO}$ prior to spectra acquisition. 1000 scans were accumulated and the resolution was set to $4 \mathrm{~cm}^{-1}$.

\section{Results and discussion}

\subsection{Stability of the $\mathrm{Fe}_{3} \mathrm{O}_{4}(111) / \operatorname{Pt}(111)$ substrate}

Fig. 1a shows an STM image of the $\mathrm{Fe}_{3} \mathrm{O}_{4}(111) / \mathrm{Pt}(111)$ substrate after preparation in UHV and transfer into air. The observed surface morphology with large terraces separated by steps is typical for these films and compares well with previous 

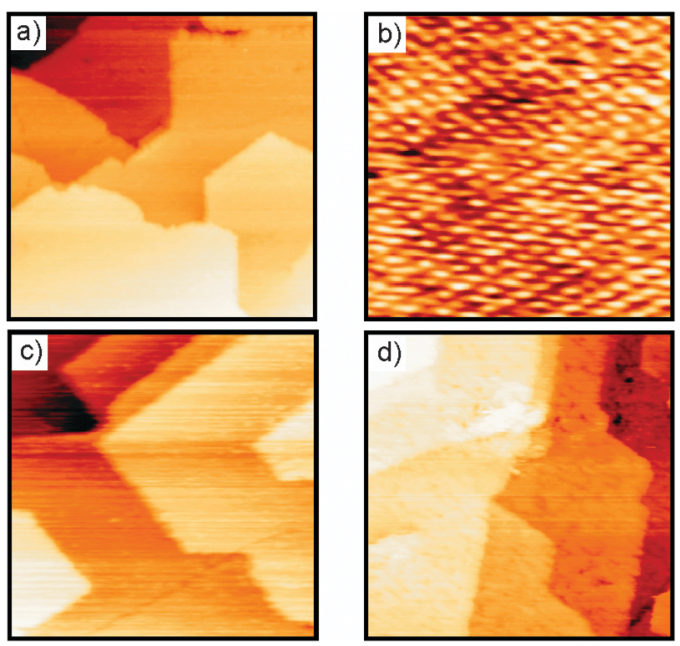

Fig. 1 STM images of freshly prepared $\mathrm{Fe}_{3} \mathrm{O}_{4}(111)$ thin films. (a) Large scale image $(100 \mathrm{~nm} \times 100 \mathrm{~nm})$; (b) detail scan $(7 \mathrm{~nm} \times 7 \mathrm{~nm})$ showing atomic periodicity resulting from the Fe within the surface layer. (c) $\mathrm{Fe}_{3} \mathrm{O}_{4}(111)$ after contact with $\mathrm{pH} 12(\mathrm{NaOH})$ solution $(100 \mathrm{~nm} \times 100 \mathrm{~nm})$. (d) After heating the surface in (c) to $600 \mathrm{~K}$ in UHV $(100 \mathrm{~nm} \times 100 \mathrm{~nm})$.

UHV investigations. ${ }^{38} \mathrm{~A}$ zoom into a terrace allows for the resolution of atomic features (Fig. 1b) with a periodicity of $\sim 0.5 \mathrm{~nm}$ originating from the surface iron layer. ${ }^{38}$ After exposure to a $\mathrm{pH} 12 \mathrm{NaOH}$ solution at room temperature, the overall surface morphology remains largely unchanged (Fig. 1c). However, while the terraces remain flat, the step edges appear somewhat more disordered. Subsequently heating this sample to $600 \mathrm{~K}$ in UHV, the temperature used to decompose the Pd hydroxide precursor in vacuum, leads to roughening of the $\mathrm{Fe}_{3} \mathrm{O}_{4}(111)$ terraces (Fig. 1d). Although no significant chemical-state changes are noted in XPS, the roughening seen in the STM image suggests that heating to $600 \mathrm{~K}$ may lead to slight reduction of the $\mathrm{Fe}_{3} \mathrm{O}_{4}$ interface. This may reflect desorption of terminal $\mathrm{OH}$ groups, which likely form during exposure to $\mathrm{NaOH}$. Unfortunately, atomically resolved images could not be obtained from the samples exposed to solution, which is likely related to some combination of the increased roughening and altered surface speciation already mentioned.

\subsection{Deposition of $\mathrm{Pd}$ on $\mathrm{Fe}_{3} \mathrm{O}_{4}(111)$ from alkaline $\mathrm{Pd}^{2+}$ solution}

Our preparation of $\mathrm{Fe}_{3} \mathrm{O}_{4}(111)$ supported $\mathrm{Pd}$ particles follows a "modified" deposition-precipitation procedure. Here, the alkaline precursor solution is directly added to the support, instead of slowly increasing the $\mathrm{pH}$ of an acidic precursor solution in contact with the support by adding base. For the following experiments, the precursor solution was obtained from a concentrated solution of acidic $\mathrm{PdCl}_{2}(20 \mathrm{mM})$, adjusted to a final $\mathrm{pH}$ of 10 and $\mathrm{Pd}^{2+}$ concentration of $2 \mathrm{mM}$ by adding $\mathrm{NaOH}$ and water. Typical UV-Vis spectra of the acidic and alkaline Pd solutions are presented in Fig. 2. The predominant $\mathrm{Pd}$ species in acidic solution are $\mathrm{PdCl}_{4}{ }^{2-}$ and $\mathrm{PdCl}_{3}\left(\mathrm{H}_{2} \mathrm{O}\right)^{-}$, as evidenced from the observed charge-transfer and $\mathrm{d}-\mathrm{d}$ transitions at $280 \mathrm{~nm} / 475 \mathrm{~nm}$ and $320 \mathrm{~nm} / 430 \mathrm{~nm}$, respectively. ${ }^{39}$ Upon hydrolysis these transitions are replaced

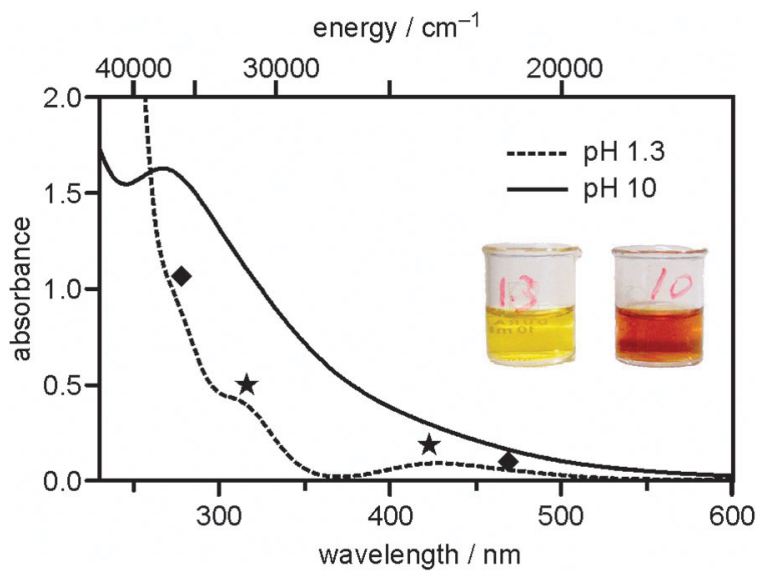

Fig. 2 UV-Vis spectra of a $\mathrm{PdCl}_{2}$ solution in acidic $(\mathrm{pH} \mathrm{1.3}$, dashed line) and alkaline ( $\mathrm{pH} \mathrm{10}$, solid line) medium. Symbols $\bullet$ and $\star$ indicate the positions of $\mathrm{d}-\mathrm{d}$ and charge transfer transitions of $\mathrm{PdCl}_{4}{ }^{2-}(\bullet)$ and $\left[\mathrm{PdCl}_{3}\left(\mathrm{H}_{2} \mathrm{O}\right)\right]^{-}(\star)$ complexes in acidic solution.

by a spectrum showing increased background absorption and a rise at short wavelengths with a feature centered at $270 \mathrm{~nm}$. Similar spectra have been reported following the basic hydrolysis of $\mathrm{H}_{2} \mathrm{PdCl}_{4}$, with the changes noted being characteristic of the formation of colloidal particles, which are commonly observed upon hydrolysis of Pd complexes. ${ }^{16,40,41}$ The exact nature of such colloids has been the subject of several studies, and it is generally agreed that they are polynuclear $\mathrm{Pd}_{n}$-hydroxo complexes (with $n=3-100$ ), which, depending on the chlorine concentration in the starting solution, might also contain chlorine ligands. ${ }^{42}$ While spectra like the one shown do provide a signature for the formation of colloidal particles, the exact assignment of the absorption feature at $270 \mathrm{~nm}$ remains a debated topic. According to Klasovsky et al. the peak relates to Plasmon excitation in the colloidal particles. ${ }^{41}$ However, Boily argues that this energy is also compatible with a charge-transfer transition of $\mathrm{Pd}$ chloro-hydroxo complexes, $\mathrm{PdCl}_{x}(\mathrm{OH})_{y}{ }^{n-}$, which, according to the hydrolysis equilibrium, are stable solution species under our experimental conditions. ${ }^{42}$ The fresh $\mathrm{pH} 10 \mathrm{Pd}$ solution was stable and the formation of a $\mathrm{Pd}(\mathrm{OH})_{2}$ precipitate was not observed over a period of several hours.

Fig. 3a (top) provides an STM image of an $\mathrm{Fe}_{3} \mathrm{O}_{4}(111)$ film following exposure to a fresh $\mathrm{pH} 10 \mathrm{Pd}$ solution for 1 hour and subsequent water rinsing/He drying at room temperature. While the surface morphology is similar to clean $\mathrm{Fe}_{3} \mathrm{O}_{4}(111)$, with the typical terrace-step structure, it exhibits slightly increased roughness relative to the clean and $\mathrm{NaOH}$-treated $\mathrm{Fe}_{3} \mathrm{O}_{4}(111)$ samples (Fig. 1a and c). Most notably, no particles are observed on this surface. Adsorbed poly-nuclear $\mathrm{Pd}$ complexes, if present, could not be resolved with STM under the present experimental conditions (and are therefore assumed to consist of a few Pd atoms at most). The corresponding XPS spectrum (Fig. 3b, top) confirms the presence of $\mathrm{Pd}$ on the $\mathrm{Fe}_{3} \mathrm{O}_{4}$ surface after exposure to $\mathrm{pH} 10 \mathrm{Pd}$ solution. The spectrum can be deconvoluted into two $\mathrm{Pd} 3 \mathrm{~d}$ doublets $\left(\operatorname{Pd} 3 \mathrm{~d}_{5 / 2}\right.$ and $\mathrm{Pd} 3 \mathrm{~d}_{3 / 2}$, with a doublet splitting of $\left.5.3 \mathrm{eV}\right)$ with $\mathrm{Pd} 3 \mathrm{~d}_{5 / 2}$ binding energies (BE) of $337.8 \mathrm{eV}$ and $336.5 \mathrm{eV}$. With XPS we also checked for residual sodium and chlorine left on the surface from the precursor solution. Both $\mathrm{Na}$ and $\mathrm{Cl}$ levels 
a) STM
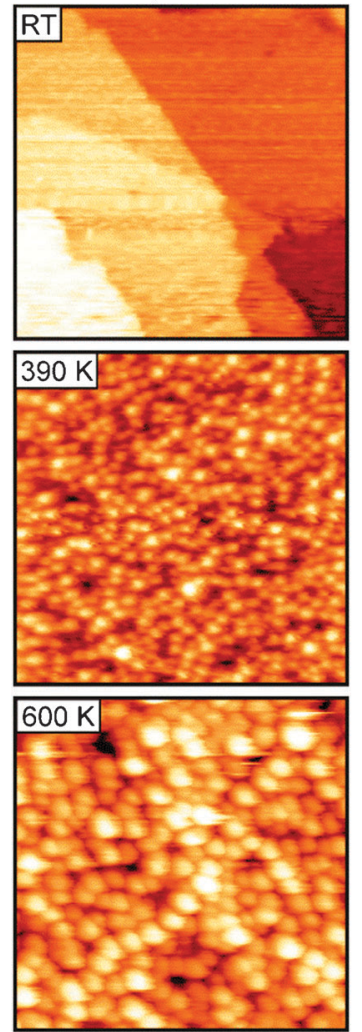

b) XPS

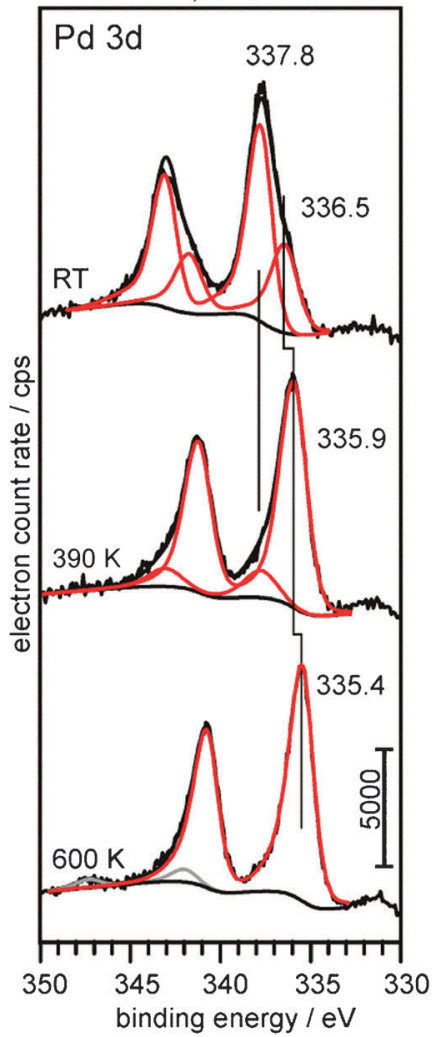

Fig. 3 (a) STM images $(100 \mathrm{~nm} \times 100 \mathrm{~nm})$ and (b) XP spectra obtained after exposure of $\mathrm{Fe}_{3} \mathrm{O}_{4}(111)$ to $\mathrm{pH} 10 \mathrm{Pd}^{2+}$ precursor solution (RT, top) and subsequent annealing to $390 \mathrm{~K}$ (middle) and $600 \mathrm{~K}$ (bottom). Fits of the individual Pd 3d XPS components are shown as red lines and the respective $\mathrm{Pd} 3 \mathrm{~d}_{5 / 2}$ binding energy values are reported. The two peaks shown as grey lines in the $600 \mathrm{~K}$ XPS spectrum result from Plasmon excitation in the metallic Pd particles.

were below the detection limit (determined to be $<0.02 \mathrm{ML}$ for $\mathrm{Na}$ and $<0.05 \mathrm{ML}$ for $\mathrm{Cl}$ ) of our XPS system, showing that these impurities have been efficiently removed during the washing step. Due to the absence of a chlorine peak in XPS, the Pd species present on the surface can be assigned to oxidic species. Indeed, the BE values observed here are in the range of values reported for hydrous and anhydrous $\mathrm{PdO}$ species $(336-338 \mathrm{eV}){ }^{43-46}$

To decompose the Pd precursor, the sample was subjected to thermal treatment under UHV conditions. Mild drying at $390 \mathrm{~K}$ leads to a drastic morphological change on the $\mathrm{Fe}_{3} \mathrm{O}_{4}(111)$ surface, which is now strewn with small particles in the size range of $2.5-3 \mathrm{~nm}$ (Fig. 3a, middle). Further annealing to $600 \mathrm{~K}$ (Fig. 3a, bottom) leads to sintering and an increase in the particle size to 3-7 $\mathrm{nm}$. The decomposition of the precursor after drying at $390 \mathrm{~K}$ is reflected in XPS by the observed intensity loss of the high $\mathrm{BE}(337.8 \mathrm{eV})$ component and the simultaneous increase of the low BE component, which slightly shifts to $335.9 \mathrm{eV}$ (Fig. 3b, middle). Upon annealing to $600 \mathrm{~K}$, the high BE component is completely absent and the XPS spectrum is dominated by one Pd component with a BE of $335.4 \mathrm{eV}$ (Fig. 3b, bottom). The latter indicates that a thermal treatment at $600 \mathrm{~K}$ is sufficient to reduce the Pd particles into the metallic state $\left(\mathrm{BE}\left(\mathrm{Pd}_{0}\right)=335.2 \mathrm{eV}^{47}\right)$. Due to the increased homogeneity of the Pd in this state, peaks resulting from photoelectron kinetic energy losses due to Plasmon excitation of metallic Pd become clearly detectable at 342.0 and $347.3 \mathrm{eV}$ (grey traces in the bottom spectrum of Fig. $3 \mathrm{~b}$ ). ${ }^{48}$

In many ways, the preparation method employed here resembles the deposition-precipitation approach reported by Haruta for the preparation of $\mathrm{Au} / \mathrm{TiO}_{2}$ catalysts, which used acidic $\mathrm{HAuCl}_{4}$ precursor solution, and a basic $\mathrm{pH}$ adjustment using $\mathrm{NaOH}$ or $\mathrm{Na}_{2} \mathrm{CO}_{3}$ (final solution $\mathrm{pH}=7-10$ ). ${ }^{49}$ As mentioned by Louis et al., this procedure does not, however, strictly correspond to deposition-precipitation because it is performed at constant $\mathrm{pH}$ under conditions where precipitation of metal-hydroxide is not favourable. ${ }^{50}$ Instead, a grafting reaction involving hydroxyl groups on the support and the suspended complexes has been suggested as the initial step in the preparation. A similar mechanism, i.e., hydrolytic adsorption of Pd chloro-hydroxo complexes at surface-bound hydroxyl groups, can be envisaged for the interaction of the alkaline $\mathrm{Pd}$ precursor solution with the $\mathrm{Fe}_{3} \mathrm{O}_{4}(111)$ substrate. If this were the only adsorption route for $\mathrm{Pd}$, then, as discussed for the case of $\mathrm{Au}$ on $\mathrm{TiO}_{2}$, metal uptake would be limited by the concentration and availability of surface $\mathrm{OH}$ groups, which would correspond to less than one monolayer when taking steric factors into account. ${ }^{50}$ However, the high Pd coverage obtained in the present experiment (Fig. 3a) indicates that additional processes, such as the adsorption of colloids present in the solution, must also occur.

To help inform our understanding of the precursor uptake processes, we turn to several recent reports, for which particular emphasis has been placed on characterization of the colloidal precursor state during the preparation of supported $\mathrm{Pd}$ catalysts. ${ }^{16,17,41,51}$ The results of these studies can be summarized as follows: the average particle size, as obtained from electron microscopy images of colloids deposited on carbon and oxide supports, is in the range of $1-2 \mathrm{~nm} \cdot{ }^{17,41,51}$ Microscopically, the colloids are reported to consist of $\left[\mathrm{Pd}(\mathrm{OH})_{2}\right]_{n}$ strands coiled up into spherical particles. ${ }^{17}$ The native colloids are X-ray amorphous, but are reported to exhibit some degree of crystallinity after deposition onto a support. ${ }^{17,41}$ However, it is important to note that adsorbed $\left[\mathrm{Pd}(\mathrm{OH})_{2}\right]_{n}$ precursor can transform into crystalline $\mathrm{PdO}$ when drying, and clearly this may play some role in the aforementioned crystallinity noted after deposition.

While the colloidal nature of the precursor solution used in our work is readily deduced from the UV-Vis spectrum shown in Fig. 2, we do not observe any specific particles on the freshly prepared sample surface by STM. We believe that this reflects the adsorption of a densely packed layer of amorphous colloids. This conclusion is supported by our XPS results, showing Pd $3 \mathrm{~d}$ binding energies consistent with the presence of Pd-hydroxide $(337.8 \mathrm{eV})$ and Pd-oxide $(336.5 \mathrm{eV})$ species after adsorption, which have also been obtained for polymer stabilized $\mathrm{PdO}_{x} \mathrm{H}_{y}$ particles deposited on carbon supports. ${ }^{41}$ The increase in the low $\mathrm{BE}$ component, its shift to a $\mathrm{BE}$ of $335.9 \mathrm{eV}$, and the concurrent loss of the high $\mathrm{BE}(337.8 \mathrm{eV})$ component after heating to $390 \mathrm{~K}$ in UHV is then consistent with decomposition of the majority of the hydroxide precursor to $\mathrm{PdO}$, which is present in the form of particles covering the entire surface. Finally, we find fully reduced Pd particles following sintering when heating further to $600 \mathrm{~K}$. Thermal decomposition of unsupported 
PdO powder is reported to occur in steps between $400 \mathrm{~K}$ and $750 \mathrm{~K}$ under UHV conditions. ${ }^{52}$ A recent EXAFS study regarding thermal reduction of $\mathrm{PdO}$ supported on high surface area $\mathrm{SiO}_{2}-\mathrm{Al}_{2} \mathrm{O}_{3}$ found that reduction of $\mathrm{PdO}$ to $\mathrm{Pd}$ was only partial at $673 \mathrm{~K}$, but complete at $873 \mathrm{~K} .{ }^{53}$ We note here that the reduction temperature depends on the nature of the support ${ }^{54}$ and that $\mathrm{Fe}_{3} \mathrm{O}_{4}$, because of its redox properties and high conductivity, may strongly aid the reduction process, giving rise to this rather low $\mathrm{PdO}$ decomposition temperature.

\subsection{Comparison with $\mathrm{PVD} \mathrm{Pd} / \mathrm{Fe}_{3} \mathrm{O}_{4}(111)$}

As shown in the previous section, deposition of $\mathrm{Pd}$ from a colloidal, alkaline $\mathrm{Pd}$ precursor solution on $\mathrm{Fe}_{3} \mathrm{O}_{4}(111)$, followed by thermal reduction at $600 \mathrm{~K}$ in vacuum, produces a model catalyst of supported metallic $\mathrm{Pd}$ nanoparticles. This surface is free of any residues from the precursor solution $\left(\mathrm{Na}^{+}, \mathrm{Cl}^{-}\right)$and can, therefore, be directly compared to a model $\mathrm{Pd} / \mathrm{Fe}_{3} \mathrm{O}_{4}(111)$ surface prepared exclusively in UHV by physical vapor deposition. Here, we choose to compare the size and shape distributions of $\mathrm{Pd}$ particles on $\mathrm{Fe}_{3} \mathrm{O}_{4}(111)$ obtained by (i) PVD of different amounts of Pd $(0.5 \AA, 2 \AA$, $4 \AA$ ), with those obtained by (ii) interaction with the $\mathrm{Pd}$ solution for various contact times (10 min, $30 \mathrm{~min}, 60 \mathrm{~min}$ ). Pd coverage and contact times have been chosen to allow direct comparison of $\mathrm{Pd}$ particles obtained by PVD and solution deposition. A summary of the results is presented in Fig. 4, where representative STM images of different coverages of Pd obtained by PVD (a-c) and by solution treatments $(\mathrm{d}-\mathrm{f})$ are shown together with the particle density (g) and size distributions $(\mathrm{h}-\mathrm{j})$ determined from these (and other) images.
The results for PVD $\mathrm{Pd}$ on $\mathrm{Fe}_{3} \mathrm{O}_{4}(111)$ are in general agreement with previous studies, ${ }^{10}$ showing a homogeneous distribution of particles across the surface and uniform particle size. The average particle sizes for the three cases studied here are $3 \mathrm{~nm}(0.5 \AA), 3.6 \mathrm{~nm}(2 \AA)$ and $5.2 \mathrm{~nm}(4 \AA)$, respectively, and a maximum particle density is reached after deposition of $2 \AA$ Pd (coverages are nominal). Slight differences relative to previous studies likely result from different deposition rates and temperatures. ${ }^{10}$ Comparison with the STM images (Fig. $4 \mathrm{~d}-\mathrm{f}$ ) and respective particle density and size distributions (Fig. 4g-j) obtained from the samples prepared in solution reveals that the two preparation procedures yield qualitatively similar Pd particles, at least in terms of their morphological properties. However, two details require further discussion. First, the maximum particle density obtained in the solution experiment exceeds that of the UHV experiment (Fig. 4g), and second, a deviation from the normal particle size distribution is observed for the sample prepared by exposure to Pd precursor solution for $60 \mathrm{~min}$ (Fig. 4h), which is also apparent from visual comparison of the STM images in Fig. 4a and d. To determine the source of these differences, we must decouple the changes attributable to the different nature of the Pd prior to binding from those relating to alteration of the support functionality when exposed to solutions instead of $\mathrm{Pd}$ atoms in UHV.

To the latter possibility, exposure of $\mathrm{Fe}_{3} \mathrm{O}_{4}(111)$ to alkaline solution leads to hydroxylation of the surface. The hydroxyl groups created are actively involved in binding the precursor complexes from solution and this largely determines the nucleation density of particles. Based on this, we presume that the higher maximum particle density obtained in the solution
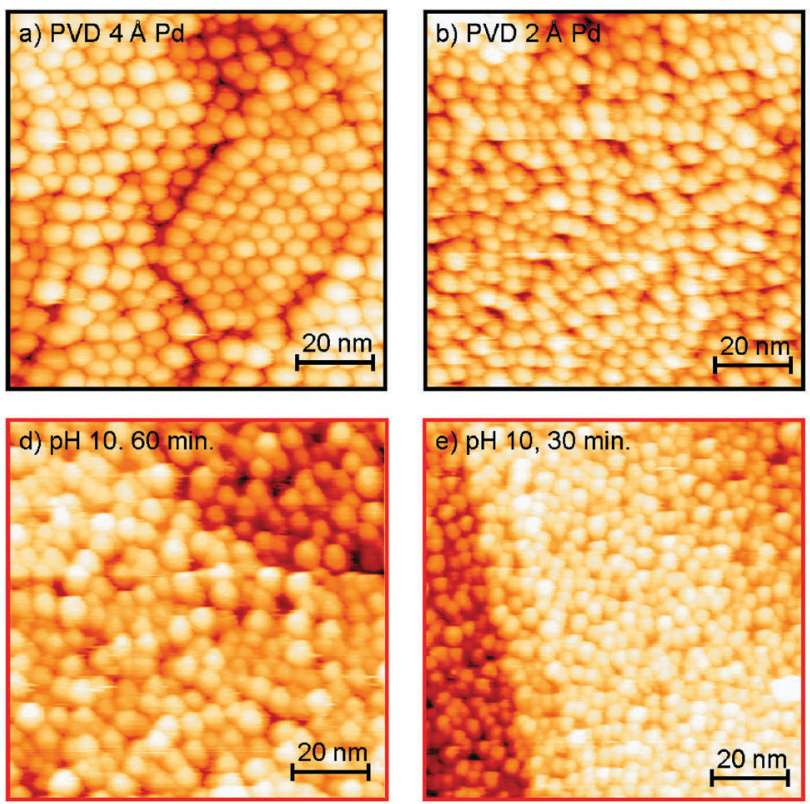
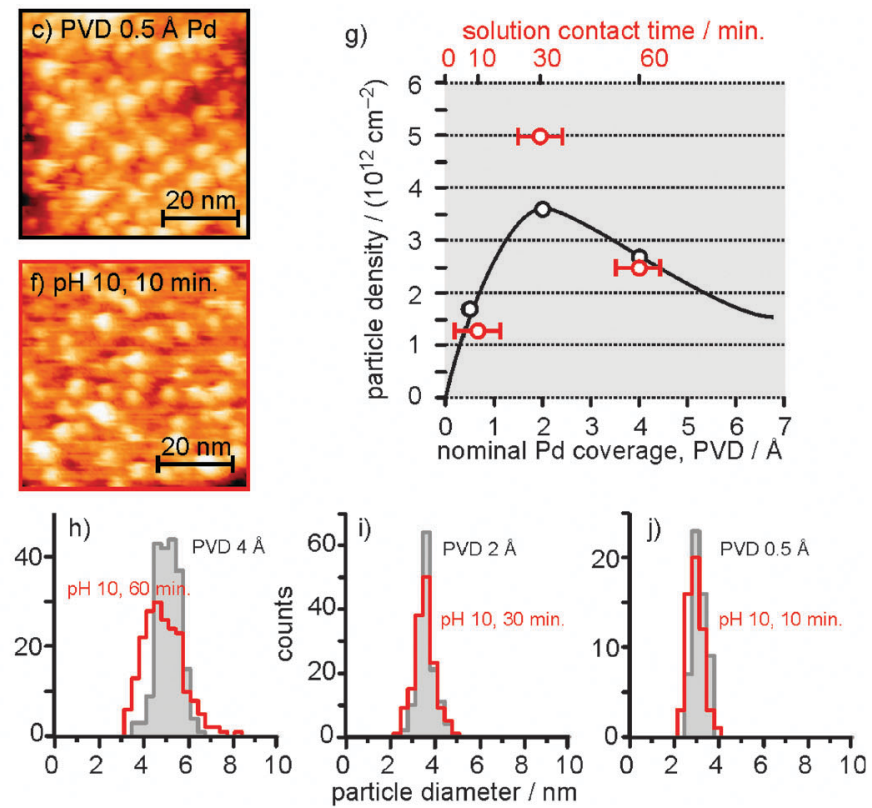

Fig. 4 STM images of Pd particles formed on $\mathrm{Fe}_{3} \mathrm{O}_{4}(111)$ after deposition of various amounts of Pd by physical vapor deposition (PVD) in UHV (a-c), and after interaction with Pd precursor solution for various contact times (d-f). (The nominal Pd loading was (a) $4 \AA$ Pd, (b) $2 \AA$ Pd, (c) $0.5 \AA$ $\mathrm{Pd}$, and the precursor interaction times were (d) $60 \mathrm{~min}$, (e) $30 \mathrm{~min}$, and (f) $10 \mathrm{~min}$.) (g) Pd particle density for the various preparations (black: PVD; red: precursor solution; red error bars indicate that Pd loadings obtained after various solution interaction times correspond approximately to the nominal Pd coverage in $\AA$ indicated in the bottom horizontal axis). (h), (i) and (j) represent the particle size distributions of samples (PVD $4 \AA$ /precursor $60 \mathrm{~min}$ ), (PVD $2 \AA$ /precursor $30 \mathrm{~min}$ ) and (PVD $0.5 \AA$ /precursor $10 \mathrm{~min}$ ), respectively. All samples were annealed to $600 \mathrm{~K}$ prior to STM imaging. Image size: (a), (b), (d), (e): $100 \mathrm{~nm} \times 100 \mathrm{~nm}$; (c), (f): $60 \mathrm{~nm} \times 60 \mathrm{~nm}$. 
experiment may be largely attributable to the greater abundance of nucleation centers under these conditions. Consistent with this, recent studies have shown that surface-bound hydroxyls strongly influence the metal nucleation and sintering behavior of $\mathrm{Au}$ on $\mathrm{MgO}$ and $\mathrm{TiO}_{2}$ supports. ${ }^{55,56}$ In addition, partial dehydroxylation during thermal treatment (Fig. 1) roughens the $\mathrm{Fe}_{3} \mathrm{O}_{4}(111)$ surface, thereby, creating a variety of adsorption sites, which may exhibit different interactions with Pd and, hence, influence sintering.

To corroborate this statement experimentally, an $\mathrm{Fe}_{3} \mathrm{O}_{4}(111)$ sample was exposed to an $\mathrm{NaOH}(\mathrm{pH}$ 12) solution to achieve a support functionality comparable to that in the Pd solution deposition experiment, and then Pd was subsequently deposited onto this chemically modified surface in UHV by vapor deposition. An STM image of the Pd particles that formed after PVD of $4 \AA$ Pd on the chemically modified $\mathrm{Fe}_{3} \mathrm{O}_{4}(111)$ surface is shown in Fig. 5a, and comparison with Fig. 4a and d reveals that the surface morphology of this sample is qualitatively similar to that obtained by precipitation of Pd-hydroxide (Fig. 4d). This result is confirmed by Fig. 5b, which shows essentially identical particle size distributions for these preparations (solid blue line: $4 \AA$ A Pd on chemically modified $\mathrm{Fe}_{3} \mathrm{O}_{4}$; dashed red line: $\mathrm{Pd} / \mathrm{Fe}_{3} \mathrm{O}_{4}$ obtained by $60 \mathrm{~min}$ exposure to precursor solution), with the same characteristic deviation from the normal size distribution of the UHV $\mathrm{Pd} / \mathrm{Fe}_{3} \mathrm{O}_{4}(111)$ sample (dashed black line). It is interesting to note that this deviation is only observed for the sample with the highest Pd coverage (60 min. deposition time, see Fig. 4), where agglomeration effects begin to play a role, as indicated by the reduced particle density compared to the maximum after only $30 \mathrm{~min}$ exposure to precursor solution (Fig. 4g). This finding suggestively corroborates the existence of a distribution of different adsorption sites on the modified support, which exhibit differing Pd-adhesion properties, and, thereby, lead to more heterogeneous sintering of $\mathrm{Pd}$ particles relative to the UHV-clean support.

In summary, comparison of $\mathrm{Fe}_{3} \mathrm{O}_{4}(111)$-supported $\mathrm{Pd}$ nano-particles, prepared either by $\mathrm{Pd}$ vapor deposition in UHV or precipitation of Pd-hydroxide from solution, reveals that the overall morphological properties are qualitatively very similar, and slight differences in maximum particle density and sinter behavior can be explained by modification of the
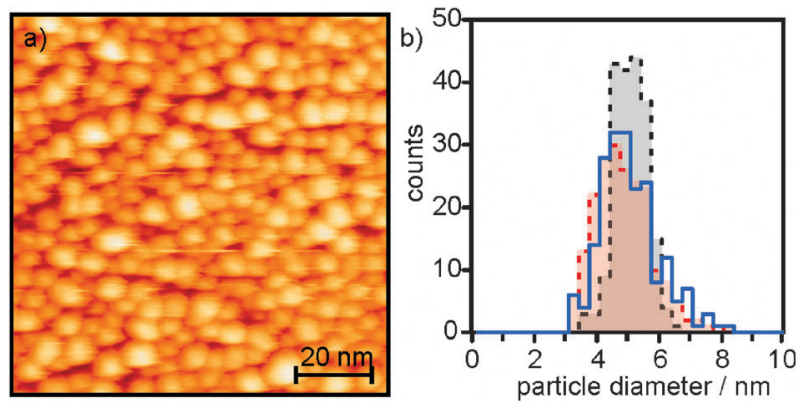

Fig. 5 (a) STM image $(100 \mathrm{~nm} \times 100 \mathrm{~nm})$ of PVD Pd on $\mathrm{Fe}_{3} \mathrm{O}_{4}(111)$, which had been chemically modified by exposure to $\mathrm{pH} 12 \mathrm{NaOH}$ solution prior to $\mathrm{Pd}$ exposure. The sample was heated to $600 \mathrm{~K}$ in UHV prior to STM imaging. (b) Particle size distribution of Pd particles formed by PVD on clean $\mathrm{Fe}_{3} \mathrm{O}_{4}(111)$ (black), interaction with Pd precursor solution for $60 \mathrm{~min}$ (red), and PVD of Pd on the chemically modified film used in (a), (blue). interfacial properties of $\mathrm{Fe}_{3} \mathrm{O}_{4}(111)$ by hydroxyl groups. As such, the nature of the precursor seems to play only a minor role in shaping the overall particle growth of $\mathrm{Pd}$ over these samples.

\subsection{Reduction, chemical characterization and the strong metal support interaction (SMSI)}

In addition to the morphological characterization presented above, we have also probed the chemical properties of the $\mathrm{Pd} / \mathrm{Fe}_{3} \mathrm{O}_{4}$ model catalysts prepared by the wet chemical approach via CO chemisorption (TPD and IRAS). Prior to chemisorption studies, the samples were subjected to an oxidation treatment $\left(1 \times 10^{-6}\right.$ mbar $\left._{2}, 600 \mathrm{~K}\right)$ to burn away carbon impurities that accumulate during exposure to air. A subsequent reduction treatment in $\mathrm{CO}\left(1 \times 10^{-6} \mathrm{mbar} \mathrm{CO}\right.$, $500 \mathrm{~K}$, followed by a short anneal to $600 \mathrm{~K}$ in UHV) was then necessary to remove chemisorbed oxygen from the palladium particles.

TPD and IRAS results obtained after exposure to $10 \mathrm{~L} \mathrm{CO}$ at $300 \mathrm{~K}$ (TPD) and $80 \mathrm{~K}$ (IRAS) are shown as black traces in Fig. 6a and Fig. 6b for CO-reduced $\mathrm{Pd} / \mathrm{Fe}_{3} \mathrm{O}_{4}(111)$ samples. The Pd particle size in the sample used here was $\sim 3 \mathrm{~nm}$. In TPD, we note a broad CO desorption signal extending from $330 \mathrm{~K}$ to $550 \mathrm{~K}$ with a maximum at $450 \mathrm{~K}$, which is typical for $\mathrm{CO}$ adsorbed on $\mathrm{Pd}{ }^{57,58}$ The presence of metallic $\mathrm{Pd}$ nanoparticles is further evidenced by the stretching frequencies noted in IRAS after adsorbing $\mathrm{CO}$ over the samples. The band at $2105 \mathrm{~cm}^{-1}$ can be assigned to $\mathrm{CO}$ adsorbed linearly (atop) on $\mathrm{Pd}$ sites at $\mathrm{Pd}(111)$ facets or defects (steps, edges), and the band at $1990 \mathrm{~cm}^{-1}$ corresponds to $\mathrm{CO}$ adsorbed on $\mathrm{Pd}$ bridge sites at particle edges or $\mathrm{Pd}(100)$ facets, respectively. ${ }^{59,60}$ The high atop/bridge intensity ratio observed in Fig. 6b is typical for small $\mathrm{Pd}$ particles and in good agreement with previous CO-IRAS data of UHV prepared $\mathrm{Fe}_{3} \mathrm{O}_{4}(111)$-supported Pd nanoparticles. ${ }^{10}$

As an alternative to $\mathrm{CO}$, we also carried out the reduction treatment in hydrogen $\left(1 \times 10^{-6}\right.$ mbar, $\left.500 \mathrm{~K}\right)$ because it is the most frequently used reducing agent in typical powder catalyst preparations. The spectroscopic results obtained after $\mathrm{H}_{2}$ reduction are shown in Fig. 6 as red traces. Following this procedure, strong suppression of $\mathrm{CO}$ adsorption above room temperature is clearly evident in the TPD (Fig. 6a), and changes in the nature of the $\mathrm{CO}$ bonds forming at lower temperatures are evident by IRAS (Fig. 6b). Namely, the two well-resolved IRAS signals at 2105 and $1990 \mathrm{~cm}^{-1}$ on CO-reduced Pd particles are replaced by three bands at 2145, 2087, and $2020 \mathrm{~cm}^{-1}$ after $\mathrm{H}_{2}$ reduction. In the corresponding photoemission spectra (Fig. $6 \mathrm{c}$ and $\mathrm{d}$ ), the $\mathrm{Pd} 3 \mathrm{~d}_{5 / 2}$ peak shifts to higher binding energy (from $335.4 \mathrm{eV}$ to $335.9 \mathrm{eV}$ for $\mathrm{CO}$ and $\mathrm{H}_{2}$ reduced, respectively) and the $\mathrm{Fe} 2 \mathrm{p}$ peak shifts to lower binding energy. In addition to the shift of the Fe $2 p$ line, a clear $\mathrm{Fe}^{2+}$ satellite peak is observed after $\mathrm{H}_{2}$ reduction (Fig. 6d).

The spectroscopic differences observed for $\mathrm{H}_{2}$ - and $\mathrm{CO}$-reduced $\mathrm{Pd} / \mathrm{Fe}_{3} \mathrm{O}_{4}(111)$ samples may indicate the presence of a Strong Metal Support Interaction or SMSI-Effect, which results in the chemical modification of supported particles via interaction with the oxide, and is expected to become more pronounced as the 

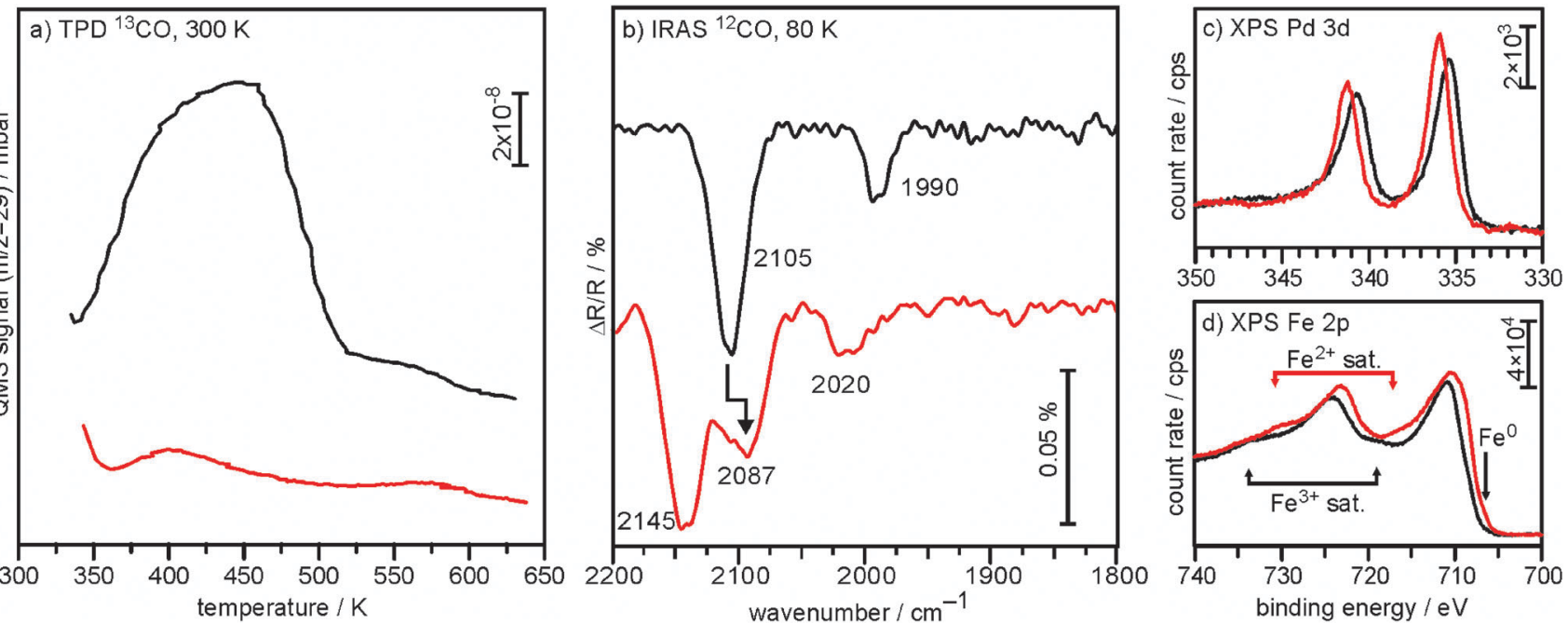

Fig. 6 Spectroscopic characterization of the $\mathrm{Pd} / \mathrm{Fe}_{3} \mathrm{O}_{4}(111)$ model catalyst prepared by impregnation with $\mathrm{pH} 10 \mathrm{Pd}^{2+}$ solution after oxidation and subsequent reduction in $\mathrm{CO}$ (black curves) or $\mathrm{H}_{2}$ (red curves). (a) ${ }^{13} \mathrm{CO}$ TPD, (b) ${ }^{12} \mathrm{CO}$ IRAS, (c) Pd $3 \mathrm{~d}$ XPS, and (d) Fe $2 \mathrm{p} \mathrm{XPS} \mathrm{spectra.}$ (The curves in a and $\mathrm{b}$ are vertically offset for clarity.)

sample is exposed to stronger reducing conditions. SMSI states were first reported for group VIII metal particles on reducible oxide supports after high temperature reductive treatment, and often manifest as some combination of metal nanoparticle encapsulation by a thin layer of oxide, ${ }^{61}$ and other types of both structural and electronic modifications to the adsorbed particles (see, e.g. ref. 62). Based on the IRAS and XPS data in Fig. 6, however, we can exclude encapsulation as a possible origin of the SMSI state for our samples. Although CO adsorption above room temperature is suppressed after $\mathrm{H}_{2}$ reduction, IRAS data recorded at low temperature show characteristic $\mathrm{CO}$ adsorption features, albeit, different from those present over regular Pd particles. Based on agreement with previously reported CO-IR data for co-deposited Pd and Fe particles on alumina ${ }^{63}$ the observed changes in the IR spectrum after $\mathrm{H}_{2}$ reduction can be explained by the formation of PdFe alloy particles, with the observed IRAS bands assigned as follows: the signal at $2087 \mathrm{~cm}^{-1}$ is indicative of atop CO-Pd binding over the PdFe bimetallic particles. The red-shift with respect to the monometallic Pd particles results from modification of the electronic structure at the binding site due to the presence of neighboring $\mathrm{Fe}$ atoms, and a reduced dipolar coupling. $\mathrm{Fe}$ atoms on the modified particles give rise to the $\mathrm{CO}$ signal at $2020 \mathrm{~cm}^{-1}$, in agreement with studies on bimetallic PdFe particles. ${ }^{63}$ The bridge-bonded CO observed on regular Pd particles at $1990 \mathrm{~cm}^{-1}$ cannot be populated on the bimetallic particles because the presence of $\mathrm{Fe}$ atoms on the particle surface results in a corresponding unavailability of multi-coordinated $\mathrm{Pd}$ sites. Instead, we now note a CO stretching frequency at $2145 \mathrm{~cm}^{-1}$, which is frequently observed for $\mathrm{CO}$ adsorbed on Pd particles which have been modified by chemisorbed oxygen. ${ }^{64,65}$ However, under the conditions of the present experiment $\left(\mathrm{H}_{2}\right.$ reduction), we can reasonably exclude the presence of a chemisorbed oxygen layer on the Pd particles. Therefore, we assign this signal to $\mathrm{CO}$ adsorbed on iron sites that are formed on the oxide support during $\mathrm{H}_{2}$ reduction.

$\mathrm{PdFe}$ alloy particle formation is further supported by the XPS results previously discussed (Fig. 6c and Fig. 6d). A shift of the $\mathrm{Pd} 3 \mathrm{~d}$ photoemission peak to higher binding energy relative to monometallic $\mathrm{Pd}$ is indicative of $\mathrm{Pd}-\mathrm{Fe}$ alloying, and has been observed previously for extended bimetallic systems as well as oxide supported bimetallic particles. ${ }^{63,66}$ Such shifts arise in part from charge transfer of electrons from $\mathrm{Pd}$ to $\mathrm{Fe}$ and $\mathrm{Pd}(4 \mathrm{~d}) \rightarrow \mathrm{Pd}(5 \mathrm{~s}, 5 \mathrm{p})$ orbital rehybridization. For such $\mathrm{PdFe}$ alloys to form, we require a certain degree of $\mathrm{Fe}$ mobility within the film, which may be achieved by the removal of $\mathrm{O}$ atoms under sufficiently reducing conditions. The Fe $2 p$ peak shifting to lower BE and the observation of a pronounced $\mathrm{Fe}^{2+}$ satellite in XPS both point to the strong reduction of the substrate from predominantly $\mathrm{Fe}^{3+}$ to $\mathrm{Fe}^{2+}$. In addition, a small shoulder appears on the $\mathrm{H}_{2}$ reduced sample at the low binding energy side at around $706 \mathrm{eV}$, which is indicative of metallic iron sites in the bimetallic particles. It has to be noted that an oxidation treatment at $500 \mathrm{~K}$ followed by reduction in $\mathrm{CO}$ is sufficient to transform the bimetallic $\mathrm{PdFe}$ particles back into regular monometallic Pd particles, showing that the SMSI effect is reversible under these conditions.

Typically, the reduction of iron oxides in hydrogen follows the sequence $\left(\mathrm{FeOOH} \rightarrow \mathrm{Fe}_{2} \mathrm{O}_{3} \rightarrow \mathrm{Fe}_{3} \mathrm{O}_{4} \rightarrow \mathrm{Fe}\right.$ ), and the reduction temperature, which is usually in the range $550-900 \mathrm{~K}$, depends on various parameters, such as preparation, and $\mathrm{H}_{2} \mathrm{O}$ partial pressure. ${ }^{67}$ The presence of metals capable of dissociating $\mathrm{H}_{2}$ (e.g. Pd) leads to lowering of the reduction temperature via spill-over of hydrogen atoms onto the support. ${ }^{68-70}$ The rather mild conditions that were shown to induce the formation of $\mathrm{PdFe}$ particles here are in agreement with such a spill-over mechanism. Although the reduction behavior and SMSI states of many catalyst materials have been investigated, rather little is known about this subject on iron oxide supported Pd particles. Previous studies reported alloy formation after reduction of $\mathrm{PdFe}$ bimetallic catalysts supported on zeolites or $\mathrm{Al}_{2} \mathrm{O}_{3},{ }^{71,72}$ and more recently, encapsulation of $\mathrm{Pd}$ has been reported after $\mathrm{H}_{2}$ reduction at $523 \mathrm{~K}$ for iron oxide supported Pd prepared by coprecipitation. ${ }^{25}$ In that case, the encapsulated Pd particles showed high activity towards low-temperature $\mathrm{CO}$ oxidation, which is conceptually similar to recent reports of high activity 
for thin $\mathrm{FeO}(111)$ layers on $\mathrm{Pt}(111)$ substrates. $^{73}$ It is interesting to note that at a similar reduction temperature, the coprecipitated sample shows a different SMSI state relative to the model system prepared in this study (encapsulation $v s$. alloy formation). A possible explanation for this difference involves the different support phases, and while oxygen released during the transformation of $\mathrm{Fe}_{2} \mathrm{O}_{3}$ into $\mathrm{Fe}_{3} \mathrm{O}_{4}$ may facilitate $\mathrm{Pd}$ encapsulation over the coprecipitated samples, a similar phase transformation is not possible in the model system described here, where partial reduction of the $\mathrm{Fe}_{3} \mathrm{O}_{4}$ surface activates alloy formation. Finally, we note that alloy formation is not exclusive to the $\mathrm{Pd} / \mathrm{Fe}_{3} \mathrm{O}_{4}$ sample prepared by the wet chemical approach, but has been observed for vapor-deposited $\mathrm{Pd}$ particles after $\mathrm{H}_{2}$ treatment as well.

\section{Conclusion}

In this study we combined ultrahigh vacuum-based procedures and analysis tools with wet chemical catalyst preparation routes to prepare and characterize a model catalyst of $\mathrm{Pd}$ nanoparticles supported on single-crystalline $\mathrm{Fe}_{3} \mathrm{O}_{4}(111)$ thin films. Via comparison of samples created in UHV with those prepared by liquid phase deposition, we have learnt that differences in the functionalization and roughness of the oxide termination play the major role in controlling $\mathrm{Pd}$ binding and nucleation behavior when deposited from $\mathrm{PdCl}_{2}$ precursors dissolved in $\mathrm{HCl}$ and suspended in basic solutions. While the colloidal nature of $\mathrm{Pd}$ complexes in these solutions is quite different from the Pd evaporated onto the surface during UHV preparations, it appears that all the memory of the initial complex is lost as the wet-chemical deposits decompose and nucleate upon UHV annealing, such that Pd growth proceeds in a similar fashion, independent of the loading technique, when the same support functionalization is present.

Reduction of the $\mathrm{Pd} / \mathrm{Fe}_{3} \mathrm{O}_{4}(111)$ surface with $\mathrm{CO}$ has been shown to result in CO chemisorption and Pd XPS properties characteristic of regular, metallic Pd particles, while a reductive treatment with hydrogen leads to the formation of PdFe alloy particles. Alloy formation results as a consequence of $\mathrm{Fe}_{3} \mathrm{O}_{4}(111)$ reduction, which is assisted by hydrogen spill-over from $\mathrm{Pd}$ onto the support. This process is completely reversible and non-alloyed $\mathrm{Pd}$ particles can be reformed by oxidation in $\mathrm{O}_{2}$ followed by reduction in $\mathrm{CO}$.

\section{Acknowledgements}

We thank Anja Seiler, Jan Rocker and Thomas Risse for making their UHV apparatus available for IRAS measurements. H.-F. W. thanks the International Max Planck Research School "Complex Surfaces in Materials Science" for a fellowship. W. E. K. is grateful to the Alexander von Humboldt foundation for financial support. This work was supported by the Cluster of Excellence "Unifying Concepts in Catalysis" sponsored by Deutsche Forschungsgemeinschaft (DFG) and administered by TU Berlin.

\section{Notes and references}

1 P. L. J. Gunter, J. W. Niemantsverdriet, F. H. Ribeiro and G. A. Somorjai, Catal. Rev. Sci. Eng., 1997, 39, 77-168.

2 G. Ertl, Surf. Sci., 1994, 299, 742-754.
3 J. A. Rodriguez and D. W. Goodman, Surf. Sci. Rep., 1991, 14, $1-107$.

4 C. T. Campbell, Surf. Sci. Rep., 1997, 27, 1-111.

5 S. M. McClure and D. W. Goodman, Top. Catal., 2011, 54, 349-362.

6 C. R. Henry, Surf. Sci. Rep., 1998, 31, 235-325.

7 T. Risse, S. Shaikhutdinov, N. Nilius, M. Sterrer and H.-J. Freund, Acc. Chem. Res., 2008, 41, 949-956.

8 H.-J. Freund, Top. Catal., 2008, 48, 137-144.

9 M. Bäumer and H.-J. Freund, Prog. Surf. Sci., 1999, 61, 127-198.

10 T. Schalow, B. Brandt, D. E. Starr, M. Laurin, S. K. Shaikhutdinov, S. Schauermann, J. Libuda and H. J. Freund, Phys. Chem. Chem. Phys., 2007, 9, 1347-1361.

11 D. O. Simone, T. Kennelly, N. L. Brungard and R. J. Farrauto, Appl. Catal., 1991, 70, 87-100.

12 N. Mahata and V. Vishwanathan, J. Catal., 2000, 196, 262-270.

13 T. Lear, R. Marshall, J. A. Lopez-Sanchez, S. D. Jackson, T. M. Klapötke, M. Bäumer, G. Rupprechter, H.-J. Freund and D. Lennon, J. Chem. Phys., 2005, 123, 174706.

14 M. L. Toebes, J. A. van Dillen and K. P. de Jong, J. Mol. Catal. A. Chem., 2001, 173, 75-98.

15 V. A. Semikolenov, Russ. Chem. Rev. (Engl. Transl.), 1992, 61, 168-174.

16 G. Agostini, E. Groppo, A. Piovano, R. Pellegrini, G. Leofanti and C. Lamberti, Langmuir, 2010, 26, 11204-11211.

17 P. A. Simonov, S. Y. Troitskii and V. A. Likholobov, Kinet. Catal., 2000, 41, 255-269.

18 N. S. Babu, N. Lingaiah, R. Gopinath, P. S. S. Reddy and P. S. S. Prasad, J. Phys. Chem. C, 2007, 111, 6447-6453.

19 W. J. Shen and Y. Matsumura, Phys. Chem. Chem. Phys., 2000, 2 , $1519-1522$.

20 S. J. Tauster, S. C. Fung and R. L. Garten, J. Am. Chem. Soc., 1978, 100, 170-175.

21 S. Y. Wang, S. H. Moon and M. A. Vannice, J. Catal., 1981, 71, $167-174$.

22 M. Bowker, P. Stone, P. Morrall, R. Smith, R. Bennett, N. Perkins, R. Kvon, C. Pang, E. Fourre and M. Hall, J. Catal., 2005, 234, 172-181.

23 L. Fan and K. Fujimoto, J. Catal., 1997, 172, 238-242.

24 N. Tsubaki and K. Fujimoto, Top. Catal., 2003, 22, 325-335.

25 H.-J. Freund, G. Meijer, M. Scheffler, R. Schlögl and M. Wolf, Angew. Chem., Int. Ed., 2011, 50, 10064-10094.

26 G. H. Zhu, K. Fujimoto, D. Y. Zemlyanov, A. K. Datye and F. H. Ribeiro, J. Catal., 2004, 225, 170-178.

27 C. T. Hong, C. T. Yeh and F. H. Yu, Appl. Catal., 1989, 48, 385-396.

28 S. Penner, H. Lorenz, W. Jochum, M. Stöger-Pollach, D. Wang, C. Rameshan and B. Klötzer, Appl. Catal., A, 2009, 358, 193-202.

29 A. A. Herzing, C. J. Kiely, A. F. Carley, P. Landon and G. J. Hutchings, Science, 2008, 321, 1331-1335.

30 X. C. Jiang and A. B. Yu, J. Mater. Process. Technol., 2009, 209, $4558-4562$.

31 B. Qiao, L. Liu, J. Zhang and Y. Q. Deng, J. Catal., 2009, 261, 241-244

32 J. M. Liu, X. G. Peng, W. Sun, Y. W. Zhao and C. G. Xia, Org. Lett., 2008, 10, 3933-3936.

33 J. H. Fischer-Wolfarth, J. A. Farmer, J. M. Flores-Camacho, A. Genest, I. V. Yudanov, N. Rösch, C. T. Campbell, S. Schauermann and H.-J. Freund, Phys. Rev. B: Condens. Matter Mater. Phys., 2010, 81, 241416.

34 T. Schalow, B. Brandt, D. E. Starr, M. Laurin, S. K. Shaikhutdinov, S. Schauermann, J. Libuda and H.-J. Freund, Angew. Chem., Int. Ed., 2006, 45, 3693-3697.

35 W. Ludwig, A. Savara, K. H. Dostert and S. Schauermann, J. Catal., 2011, 284, 148-156.

36 W. Weiss and M. Ritter, Phys. Rev. B: Condens. Matter Mater. Phys., 1999, 59, 5201-5213.

37 M. Wilms, M. Kruft, G. Bermes and K. Wandelt, Rev. Sci. Instrum., 1999, 70, 3641-3650.

38 S. K. Shaikhutdinov, M. Ritter, X. G. Wang, H. Over and W. Weiss, Phys. Rev. B: Condens. Matter Mater. Phys., 1999, 60, 11062-11069.

39 L. I. Elding, Inorg. Chim. Acta, 1972, 6, 647-651.

40 T. Harada, S. Ikeda, M. Miyazaki, T. Sakata, H. Mori and M. Matsumura, J. Mol. Catal. A: Chem., 2007, 268, 59-64. 
41 F. Klasovsky, P. Claus and D. Wolf, Top. Catal., 2009, 52, $412-423$.

42 J.-F. Boily, T. M. Seward and J. M. Charnock, Geochim. Cosmochim. Acta, 2007, 71, 4834-4845.

43 K. S. Kim, A. F. Gossmann and N. Winograd, Anal. Chem., 1974, 46, 197-200.

44 C. Furlani, G. Mattogno and V. Sessa, J. Less-Common Met., 1984, 102, 89-96.

45 K. Otto, L. P. Haack and J. E. de Vries, Appl. Catal., B, 1992, 1, $1-12$.

46 T. Pillo, R. Zimmermann, P. Steiner and S. Hüfner, J. Phys.: Condens. Matter, 1997, 9, 3987-3999.

47 NIST X-ray Photoelectron Spectroscopy (XPS) Database, Version 3.5. http://srdata.nist.gov/xps.

48 F. P. Netzer and M. M. El Gomati, Surf. Sci., 1983, 124, 26-38.

49 S. Tsubota, D. A. H. Cunningham, Y. Bando and M. Haruta, Stud. Surf. Sci. Catal., 1995, 91, 227-235.

50 R. Zanella, L. Delannoy and C. Louis, Appl. Catal., A, 2005, 291, 62-72.

51 B. Didillon, E. Merlen, T. Pages and D. Uzio, Stud. Surf. Sci. Catal., 1998, 118, 41-54.

52 M. Peuckert, J. Phys. Chem., 1985, 89, 2481-2486.

53 G. Agostini, R. Pellegrini, G. Leofanti, L. Bertinetti, S. Bertarione, E. Groppo, A. Zecchina and C. Lamberti, J. Phys. Chem. C, 2009, 113, 10485-10492.

54 R. J. Farrauto, J. K. Lampert, M. C. Hobson and E. M. Waterman, Appl. Catal., B, 1995, 6, 263-270.

55 M. A. Brown, Y. Fujimori, F. Ringleb, X. Shao, F. Stavale, N. Nilius, M. Sterrer and H.-J. Freund, J. Am. Chem. Soc., 2011, 133, 10668-10676.
56 G. M. Veith, A. R. Lupini and N. J. Dudney, J. Phys. Chem. C, 2009, 113, 269-280.

57 X. C. Guo and J. T. Yates, J. Chem. Phys., 1989, 90, 6761-6766.

58 I. Stará and V. Matolín, Surf. Sci., 1994, 313, 99-106.

59 D. R. Rainer, M. C. Wu, D. I. Mahon and D. W. Goodman, J. Vac. Sci. Technol., A, 1996, 14, 1184-1188.

$60 \mathrm{~K}$. Wolter, O. Seiferth, H. Kuhlenbeck, M. Bäumer and H.-J. Freund, Surf. Sci., 1998, 399, 190-198.

61 S. J. Tauster, Acc. Chem. Res., 1987, 20, 389-394.

62 J. Y. Liu, ChemCatChem, 2011, 3, 934-948.

63 M. P. Felicissimo, O. N. Martyanov, T. Risse and H.-J. Freund, Surf. Sci., 2007, 601, 2105-2116.

64 X. P. Xu and D. W. Goodman, J. Phys. Chem., 1993, 97, 7711-7718.

65 T. Schalow, B. Brandt, D. E. Starr, M. Laurin, S. Schauermann, S. Shaikhutdinov, J. Libuda and H.-J. Freund, Catal. Lett., 2006, 107, 189-196.

66 J. A. Rodriguez, R. A. Campbell and D. W. Goodman, Surf. Sci., 1994, 307, 377-383.

67 O. J. Wimmers, P. Arnoldy and J. A. Moulijn, J. Phys. Chem., 1986, 90, 1331-1337.

68 J. E. Benson, H. W. Kohn and M. Boudart, J. Catal., 1966, 5, 307-313.

69 K. M. Sancier and S. H. Inami, J. Catal., 1968, 11, 135-142.

70 P. A. Sermon and G. C. Bond, Catal. Rev. Sci. Eng., 1973, 8, 211-239.

71 L. Q. Xu, G. D. Lei, W. M. H. Sachtler, R. D. Cortright and J. A. Dumesic, J. Phys. Chem., 1993, 97, 11517-11523.

72 R. L. Garten and D. F. Ollis, J. Catal., 1974, 35, 232-246.

73 Y. N. Sun, Z. H. Qin, M. Lewandowski, E. Carrasco, M. Sterrer, S. Shaikhutdinov and H.-J. Freund, J. Catal., 2009, 266, 359-368. 